\title{
Ileo uterine fistula following hayman stitch application
}

\author{
Haritha Sagili* and S Murali \\ Department of Obstetrics and Gynaecology, JIPMER, Pondicherry, India
}

\begin{abstract}
Uterine compression sutures like B-Lynch brace suture and Hayman stitch are being increasingly used in the management of intractable postpartum hemorrhage due to uterine atony. These conservative procedures may result in complications like pyometra. We are reporting a case of ileo uterine fistula which presented 2 months after evacuation of infected uterine contents in a patient with Hayman stitch.
\end{abstract}

\section{Introduction}

Postpartum hemorrhage (PPH) due to uterine atony is a major contributor to maternal mortality and morbidity in developing countries [1]. Uterine compression sutures like B-Lynch brace suture and Hayman stitch have emerged as alternatives to hysterectomy in this condition [2,3]. Hayman stitch has the advantage of being easier and we can avoid opening lower uterine segment in cases of PPH following vaginal delivery. However there are only few studies describing the short term and long term outcomes following application of Hayman stitch [4]. Further, with this technique there is a risk of blood getting trapped within the uterine cavity and may result in complications. In this article we describe a case of Ileo uterine fistula which developed after application of Hayman stitch in a patient with intractable PPH.

\section{Case report}

A 23 year primigravida at 38 weeks of gestation was admitted in view of Oligohydramnios and intrauterine growth restriction. Cervical ripening was done with intracervical Prostaglandin $\mathrm{E}_{2}$ gel. In active stage of labor, there were recurrent late decelerations in fetal heart rate and liquor was found to be meconium stained. Emergency Cesarean section was done in view of fetal distress. Active management of third stage of labor with intramuscular oxytocin was done. After uterine closure, uterus became atonic. There was no response to oxytocin, methyl ergometrine and 15 methyl PGF2a. Bilateral uterine artery ligation also failed to control the bleeding. Decision to apply Hayman stitch was taken. Hayman stitch was applied using No 1 catgut suture and bleeding was controlled. Blood loss was about $1.5 \mathrm{~L}$. She received 2 units of packed red blood cells. A live, $2.3 \mathrm{~kg}$, female baby was born. Baby was intubated and shifted to Neonatal Intensive Care Unit for resuscitation.

Postoperatively, patient developed high febrile spikes from the fifth day of surgery. Ultrasound of pelvis detected pyometra. She was started on broad spectrum antibiotics and cervical dilatation and pyometra drainage was done on post operative day 9. Pus culture showed growth of Escherichia coli and Enterococcus faecalis. She was given appropriate antibiotics with which her fever subsided. She was discharged on post operative day 18.

Two months later she presented with complaint of passing faeces through vagina.
Computed tomography with oral contrast study showed Ileouterine fistula (Figures 1 and 2).

Patient was taken up for exploratory laparotomy. Intra operatively ileo-uterine fistula was noted (Figures 3 and 4). A $2 \mathrm{~cm}$ dense adhesion between distal ileum and fundus of uterus was noted. Adhesiolysis was done and edges of uterine rent were freshened and approximated with 2-0 polyglactin interrupted sutures. Loop ileostomy was done. She was discharged on post operative day 10 .

The patient is on regular follow up and underwent a reversal of loop ileostomy after 2 months. Baby died 3 days after delivery due to Hypoxic ischaemic encephalopathy.

\section{Discussion}

B-Lynch suture has been the most commonly used and studied uterine compression suture $[5,6]$. Hayman stitch and Cho technique of multiple square sutures are the other commonly used uterine

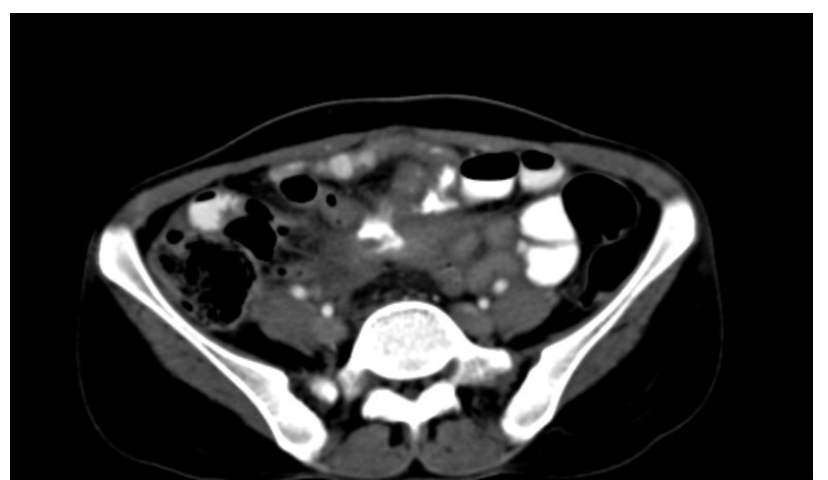

Figure 1. Computed tomography of pelvis with oral contrast shows contrast filled ileum looping around the uterus.

Correspondence to: Haritha Sagili, Associate Professor, Department of Obstetrics and Gynaecology, JIPMER, Pondicherry, 605005, India; Tel: 0091-9489390630; Fax: 0091-413-2272735; E-mail: harithasagili@gmail.com

Key words: hayman stitch, ileouterine fistula

Received: January 12, 2016; Accepted: February 22, 2016; Published: February 24,2016 


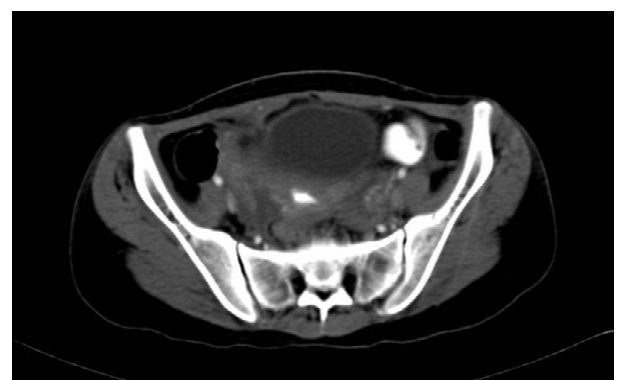

Figure 2. Oral contrast in the endometrial cavity consistent with ileo uterine fistula.

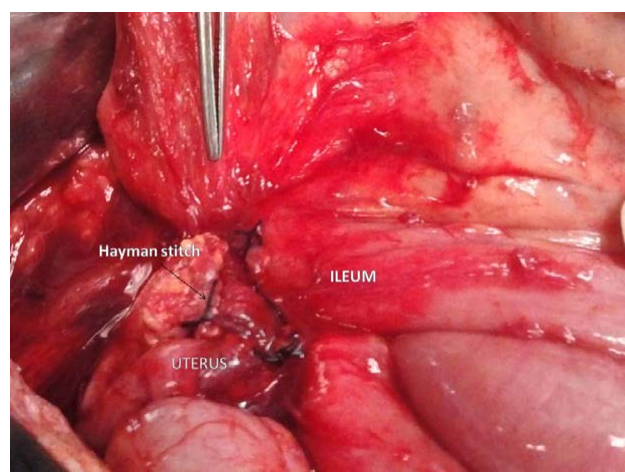

Figure 3. Intraoperative picture showing dense adhesions between ileum and uterus.

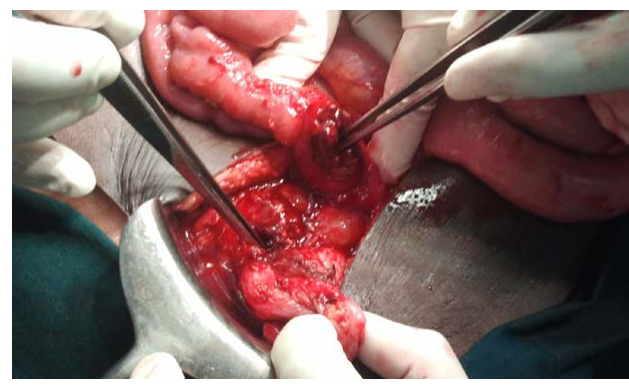

Figure 4. Division of these adhesions reveal ileo uterine fistula.

compression sutures [7]. These procedures are not always without complications. Asherman syndrome and partial ischemic necrosis of uterus have been reported after B-Lynch suture application [8,9]. According to Allam et al, a compression test to confirm the potential efficacy of the B-Lynch suture before its application and the correct application of the suture with even distribution of the tension across the uterine body can prevent most of the complications [10]. No case of pyometra development has been reported after application of B-Lynch suture. Pyometra and subsequent hysterectomy has been reported after Cho technique [11]. It has been suggested that the risk of pyometra is also present with Hayman stitch [12,13]. In our study we are reporting the first case of pyometra development after Hayman stitch application. As hysterotomy is not performed, blood clots may get trapped in the uterine cavity as stitch is being applied. They may get subsequently infected resulting in pyometra. In our patient, pyometra was detected on day 5. A small uterine perforation might have developed during drainage of this pyometra. A loop of ileum might have got stuck to this part of the infected uterus. This was undetected till the patient presented with foul smelling discharge after 2 months due to formation of ileo uterine fistula. Draining of pyometra under ultrasound guidance and early detection of uterine perforation could have prevented this complication. We feel use of B-Lynch suture instead of Hayman stitch may have prevented pyometra formation. Nanda et al. in a retrospective study reported the outcome of 48 women with Hayman stitch [4]. They could avoid hysterectomy in $93.75 \%$ of patients and none of them developed pyometra. They have suggested that collection of blood clots within the uterine cavity can be prevented by applying bimanual compression to the uterus at the time of suture placement. In our patient despite application of bimanual compression, pyometra developed. Long term data after application of B-Lynch suture is available which indicate good reproductive outcome [5]. There is only limited data regarding the safety and reproductive outcome in case of other compression sutures like Hayman stitch. To conclude, pyometra formation is one of the potential complications of Hayman stitch application. Extreme caution should be exercised when draining pyometra to avoid further complications.

\section{Conclusions}

Hayman stitch application may result in pyometra formation. Drainage of pyometra under ultrasound guidance may reduce the chances of uterine perforation. Early detection of uterine perforation is necessary to prevent complications like ileo uterine fistula.

\section{References}

1. Khan KS, Wojdyla D, Say L, Gulmezoglu AM, Van Look PF (2006) WHO analysis of causes of maternal death: a systemic review. Lancet 367: 1066-1074. [Crossref]

2. Lynch CB, Coker A, Lawal A, Abu J, Cowen M (1997) The B-Lynch surgical technique for the control of massive postpartum haemorrhage: an alternative to hysterectomy? Five cases reported. Br J Obstet Gynecol 104: 372-375. [Crossref]

3. Hayman RG, Arulkumaran S, Steer PJ (2002) Uterine compression sutures: surgical management of post partum hemorrhage. Obstet Gynecol 99: 502-506. [Crossref]

4. Nanda S, Singhal SR (2011) Hayman uterine compression stitch for arresting atonic postpartum hemorrhage: 5 year's experience. Taiwan J Obstet Gynecol 50: 179-181. [Crossref]

5. Fuglsang J (2014) Later reproductive health after B-Lynch sutures: a follow-up study after 10 years' clinical use of the B-Lynch suture. Fertil Steril 101: 1194-1199. [Crossref]

6. Cowan AD, Miller ES, Grobman WA (2014) Subsequent Pregnancy Outcome after B-Lynch Suture Placement. Obstet Gynecol 124: 558-561. [Crossref]

7. Cho J, Jun H, Lee C (2000) Hemostatic suturing technique for uterine bleeding during cesarean delivery. Obstet Gynecol 96: 129-131. [Crossref]

8. Joshi VM, Shrivastava M (2004) Partial ischemic necrosis of the uterus following a uterine brace compression suture. BJOG 111: 279-280. [Crossref]

9. Rathat G, Do Trinh P, Mercier G, Reyftmann L, Dechanet C, et al. (2011) Synechia after uterine compression sutures. Fertil Steril 95: 405-409.

10. Allam MS, B-Lynch (2005) The B-Lynch and other uterine compression suture techniques. Int J Gynaecol Obstet 89: 236-241.

11. Ochoa M, Allaire A, Stitely M (2002) Pyometra after hemostatic square suture technique. Obstet Gynecol 99: 506-509.

12. B-Lynch C (2005) Correspondence. Br J Obstet Gynaecol 112: 126

13. Cotzias C, Girling J (2005) Uterine compression suture without hysterotomy-why a non-absorbable suture should be avoided. J Obstet Gynecol 25: 150-152. [Crossref]

Copyright: (C2016 Sagili H. This is an open-access article distributed under the terms of the Creative Commons Attribution License, which permits unrestricted use, distribution, and reproduction in any medium, provided the original author and source are credited. 